\title{
A Review on Corrosion Resistant of Cu-Al Joints
}

\section{Winmin Long*}

State Key Laboratory of Novel Brazing Materials and Technology, Zhengzhou Institute of Machinery, Zhengzhou, P. R. China

\begin{abstract}
This paper discussed the research profile on corrosion resistance of $\mathrm{Cu}-\mathrm{Al}$ joints. The review indicated that it was difficult to avoid the corrosion formation in the $\mathrm{Cu}-\mathrm{Al}$ joint due to the heterogeneous chemical composition and structure. Factors influencing the corrosion resistance of $\mathrm{Cu}-\mathrm{Al}$ joints could be divided into three categories, the first one is the effect of alloy itself (such as alloy composition, mixed impurities, alloy structure, heat treatment, metal surface condition, stress and strain), the second one is the effect of the surrounding environment (such as corrosion medium, temperature and stress) and the last one is the effect of equipment design and process and anti-corrosion measures (such as spray coating). Hence excellent joints with high-corrosion resistance could be ensured if researchers could take a good use of these factors. Finally, suggestions about the further research orientation on $\mathrm{Cu}-\mathrm{Al}$ corrosion protection were given.
\end{abstract}

Keywords: $\mathrm{Cu}-\mathrm{Al}$ joints; Corrosion resistance; Electronic industries

\section{Introduction}

Substitution of aluminum for copper is increasingly used in marine, automotive and electric and electronic industries since their excellent advantages of light weight and low production cost. Hence copper-aluminum connectors were largely introduced in the process of industrial production $[1,2]$. It is difficult to made a stable and reliable copper-aluminum joint due to these difference between $\mathrm{Cu}$ and $\mathrm{Al}$ such as large melting point difference, thermal expansion coefficient, electrode potential and mass formation of brittle intermetallic compounds. Besides, the intermetallic compounds formed in the joint are very different with both $\mathrm{Cu}$ and $\mathrm{Al}$ in these aspects. To solve these joining problems, many joining technologies were employed [3]. Flash welding was firstly utilized to join copper to aluminum, [4] and then other welding technologies were employed, such as diffusion welding, friction welding, friction stir welding, laser beam welding and ultrasonic welding [5-8]. However the problem of $\mathrm{Cu}-\mathrm{Al}$ joints corrosion is still existing and it deteriorate the properties of $\mathrm{Cu}$ - $\mathrm{Al}$ joints, which severely shorten the service life of components.

In this paper, some preeminent research on $\mathrm{Cu}-\mathrm{Al}$ joints corrosion was reviewed. The corrosion forms and mechanism were discussed. Factors influencing the corrosion process were summarized. The efficient methods used to modified the corrosion resistance of the $\mathrm{Cu}$ $\mathrm{Al}$ joint were listed.

\section{Corrosion forms in $\mathrm{Cu}-\mathrm{Al}$ joints}

The common corrosion forms occurring in the metallic materials include pitting corrosion, intergranular corrosion, stress corrosion, corrosion fatigue and high temperature corrosion as shown in Figure 1 [9-11]. The chemical composition and structure in metallic materials were not homogeneous, which were responsible for the corrosion potential difference between different phase. The pitting corrosion occurred in the metallic materials when it was immersed in a electrolyte solution [11]. For example, Xue-hui Wang et al investigated the pitting corrosion behavior of 7A60 aluminum alloy in $3.5 \% \mathrm{NaCl}$ solution. Results showed that pitting corrosion always initiated in the electrochemical active $\mathrm{MgZn}_{2}$ region, and followed by $\mathrm{Al}_{2} \mathrm{MgCu}$ and $\mathrm{Mg}_{2} \mathrm{Si}$ [12]. In the process of welding, the introduction of lots of heat input into metallic materials destroyed the chemical and electrochemical balance between grains and grain boundary and increased the tendency of intergranular corrosion [12]. For the stress corrosion, there was still no uniform explanation. But the formation of stress corrosion must meet this two requirements, namely corrosion attack and the existence of stress [13]. Corrosion fatigue and fatigue are different. Corrosion fatigue did not have corrosion fatigue limit compared with fatigue [14]. Metal oxidation is the main corrosion mechanism of high temperature corrosion. High temperature provides enough energy to make metal oxidized, which cannot happen at room temperature [15]. As mentioned above, electrochemical corrosion is the primary problem for $\mathrm{Cu}-\mathrm{Al}$ joints corrosion. Hence it is important to study electrochemical corrosion mechanism to ensure the enough service life of $\mathrm{Cu}-\mathrm{Al}$ joints.

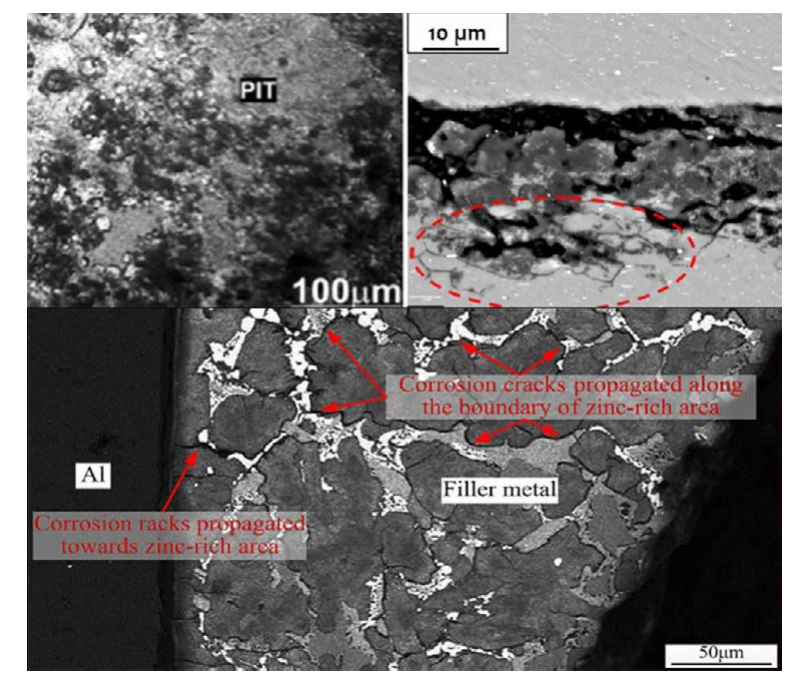

Figure 1: Common corrosion forms. (a) pitting corrosion, (b) intergranular corrosion, (c) stress corrosion.

${ }^{*}$ Corresponding author: Winmin Long, State Key Laboratory of Novel Brazing Materials and Technology, Zhengzhou Institute of Machinery, Zhengzhou, P. R. China, Tel: 037167710950; E-mail: longwm@zrime.com.cn

Received December 12, 2017; Accepted December 29, 2017; Published January 05, 2018

Citation: Long W (2018) A Review on Corrosion Resistant of Cu-Al Joints. Ind Eng Manage 7: 247. doi:10.4172/2169-0316.1000247

Copyright: (c) 2018 Long W. This is an open-access article distributed under the terms of the Creative Commons Attribution License, which permits unrestricted use, distribution, and reproduction in any medium, provided the original author and source are credited. 


\section{Corrosion Mechanism in $\mathrm{Cu}-\mathrm{Al}$ joints}

As mentioned above, the main cause of electrochemical corrosion is the heterogeneous chemical composition and microstructure in the $\mathrm{Cu}-\mathrm{Al}$ joint, which in turn constitute the cathode and anode of electrochemical corrosion. From the $\mathrm{Cu}-\mathrm{Al}$ phase diagram, IMCs $\mathrm{CuAl}_{2}, \mathrm{CuAl}, \mathrm{Cu}_{3} \mathrm{Al}_{2}, \mathrm{Cu}_{4} \mathrm{Al}_{3}$ and $\mathrm{Cu}_{9} \mathrm{Al}_{4}$ are likely to be formed in the $\mathrm{Cu}-\mathrm{Al}$ joint [2]. Lim et al. investigated the corrosion behavior of $\mathrm{CuAl}_{2}$, $\mathrm{CuAl}, \mathrm{Cu}_{9} \mathrm{Al}_{4}, \mathrm{Cu}$ and $\mathrm{Al}$ in an acidic chlorine solution, and results indicated that $\mathrm{Cu}_{9} \mathrm{Al}_{4}$ was most susceptive to corrosion compared with $\mathrm{CuAl}$ and $\mathrm{CuAl}_{2}$. Besides, the impedance of these phases followed the descending order of $\mathrm{Al} \mathrm{CuAl}, \mathrm{CuAl}_{2}, \mathrm{Cu}_{9} \mathrm{Al}_{4}$ and $\mathrm{Cu}$. And the corrosion current of these phases followed the order $\mathrm{Cu}<\mathrm{Cu}_{9} \mathrm{Al}_{4}<\mathrm{CuAl}_{2}<\mathrm{CuAl}$ $<\mathrm{Al}$. It meant that $\mathrm{Cu}$ had the lowest electrode potential and excellent corrosion resistance. $\mathrm{Al}$ was contrary, which was in agreement with Moghaddam et al. results [16,17]. Shi et al. found that $\mathrm{Al}$ always be an anode and involved the $\mathrm{Al}$ dissolution, conforming the eqn. (1), and the other phases played a role of the cathode, which conforming the eqn. (2) [18]

$$
\mathrm{Al}-3 \mathrm{e}=\mathrm{Al} 3+
$$

\section{$\mathrm{O} 2+2 \mathrm{H} 2 \mathrm{O}+4 \mathrm{e}=4 \mathrm{OH}-$}

For the $\mathrm{Cu}-\mathrm{Al}$ IMCs corrosion resistance, Adeline Lim et al thought that the number of $\mathrm{Al}$ atoms in the empirical formula was the main reason. Hence $\mathrm{Cu}_{9} \mathrm{Al}_{4}$ had the highest corrosion susceptibility, followed by $\mathrm{CuAl}$ and $\mathrm{CuAl}_{2}$.

For the stress corrosion mechanism, there were several main views. We only introduced of one of them in detail, that was the theory of film rupture, suggested by Logan. The crack initiation occurred when the surface layer of $\mathrm{Cu}-\mathrm{Al}$ joints was damaged by electrochemical effect or mechanical effect. Because the surface damage could generate electrochemical corrosion, which led to localized anodic dissolution. And then the crack propagated along the grain boundary. The stress resulted from dislocation pile-up generated on the grain boundary resulted in the dissolution of passivation layer, which in turn promoted the formation of the stress through the generation, propagation, and movement of dislocation. The film rupture theory suggested a repeating, cycling process of film rupture, underlying alloy dissolution and passivation [19]. Besides, Edeleanu and Forty raised the theory of fracture-induced cleavage [20], Jones suggested the theory of localized surface plasticity, Galvele et al. suggested the theory of Atomic surface mobility [21].

From this section, $\mathrm{Cu}-\mathrm{Al} \mathrm{IMCs}$ promoted the corrosion process of joints due to the heterogeneous chemical composition and microstructure. Stress corrosion cracks formed when the stress and corrosion attack was interacting.

\section{Factors Influencing Corrosion Process}

Numerous research on $\mathrm{Cu}-\mathrm{Al}$ joints corrosion had been done to investigate the factors impacting corrosion. The investigation results showed that these factors could be divided into three categories. The first one was the effect of alloy itself, such as alloy composition, mixed impurities, alloy structure, heat treatment, metal surface condition, stress and strain. For instance, Ye et al. examined the corrosion behavior of $\mathrm{Cu}-\mathrm{Al}$ joints brazed with $\mathrm{Zn}-\mathrm{Al}-\mathrm{Si}$ and $\mathrm{Zn}-\mathrm{Al}$ filler metals respectively. The results they obtained indicated that the shear strength of the joints brazed with $\mathrm{Zn}$-Al-Si filler metal maintained $34 \mathrm{MPa}$ after salt spray for 42 days, but that brazed with $\mathrm{Zn}-22 \mathrm{Al}$ fractured after 15 days. Besides, Si element addition could inhibit the propagation of corrosion cracks because the formation of the Al-Si eutectic made the diffusion layer thinner and refined the microstructure in the joint [9]. Both $\mathrm{Wu}$ et al. and Lim et al. studied the effect of Pd element on the corrosion behavior of $\mathrm{Cu}-\mathrm{Al}$ joints $[17,22]$. Wu et al. research implied that Pd element addition could enhance the corrosion resistance of $\mathrm{Cu}-\mathrm{Pd}$ phase in the $\mathrm{Cu}-\mathrm{Al}$ joint when $\mathrm{NaCl}$ concentration was given [22]. And corrosion resistance was increased with the increasing $\mathrm{Pd}$ content because the enrichment of Pd element on the corrosion surface restrained the anode dissolution. For Pd-bearing Cu9Al4 IMC in the $\mathrm{Cu}-\mathrm{Al}$ joint, $\mathrm{Pd}$ addition reduced the extent of $\mathrm{Al}$ passivation, which in turn increased corrosion current density. Hence the corrosion resistance could be slightly improved. Osorio et al. investigated the effect of tool profile on the corrosion behavior of $\mathrm{Cu}-\mathrm{Al}$ joints and results showed that grain coarsening was beneficial to improvement of corrosion resistance due to the reduction of the galvanic coupling [23]. Osorio et al. researched the effect of Cu-based IMC on the corrosion behavior of $\mathrm{Cu}-\mathrm{Al}$ alloy [23]. They found that the corrosion resistance of $\mathrm{Cu}-\mathrm{Al}$ joints was improved when anode/cathode area ratio transformed from 9:1 to 3:1. Because a proper ratio could enhance the enveloping effect, which in turn modified the corrosion resistance of $\mathrm{Cu}-\mathrm{Al}$ joints. Besides, they thought that enveloping effect was the main reason of the improvement of corrosion resistance from grain coarsening. Another research from Rao et al. indicated that heat input could promote the dissolution of strengthening precipitates and thereby improve the corrosion resistance of $\mathrm{Cu}-\mathrm{Al}$ joints [24]. Rao et al. found that heat input could enhance the corrosion resistance of $\mathrm{Cu}-\mathrm{Al}$ joints due to the improvement of the homogeneity of chemical composition and structure [14]

The second one was the effect of environment, such as corrosion medium, temperature and stress. Rao et al. study showed that the value of $\mathrm{NaCl}$ concentration had an obvious effect on the corrosion resistance of $\mathrm{Cu}-\mathrm{Al}$ joints. The higher the $\mathrm{NaCl}$ concentration was, the lower corrosion resistance become as shown in Figure 2 [22]. Warner et al. examined the effect of the addition of molybdate into $\mathrm{NaCl}$ and $\mathrm{HCl}$ solution on corrosion fatigue cracks. Results indicated that molybdate addition could availably restrain the expansion of corrosion fatigue cracks since molybdate can stabilize the passive film at the crack tip, which in turn reduced $\mathrm{H}$ generation and absorption [25].

The last one was the effect of equipment design and process and anti-corrosion measures. For instance, Rao et al. examined the effect of tool profile on the corrosion behavior of $\mathrm{Cu}-\mathrm{Al}$ welded nugget joined by using friction stir welding. They found that the pitting corrosion

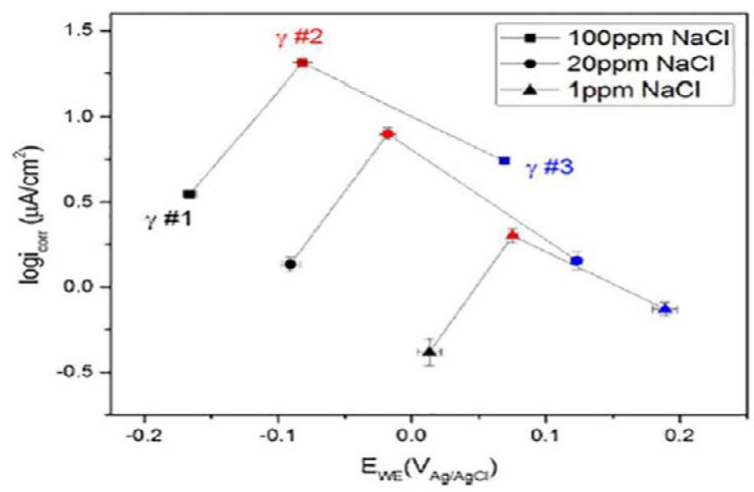

Figure 2: Effect on $\mathrm{NaCl}$ concentration corrosion resistance of $\mathrm{Cu}-\mathrm{Al}$ joints. 
potential value of stir area processed changed with using different tools as shown in Figure 3 and Table 1 [24]

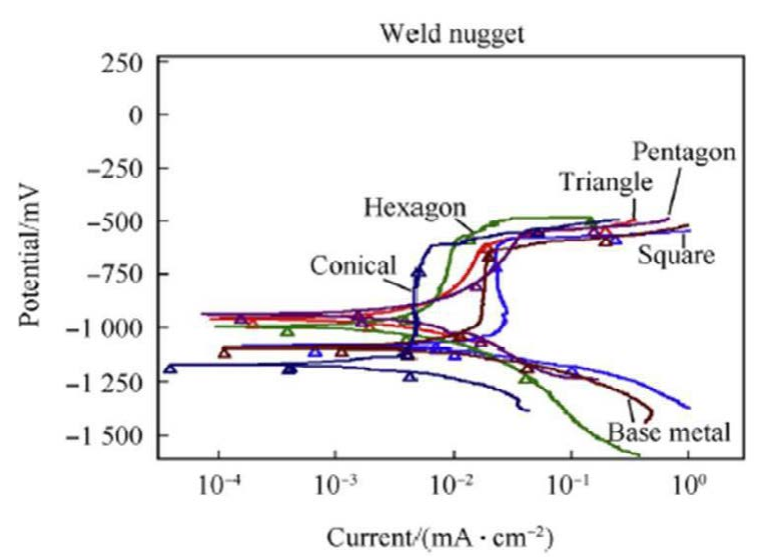

Figure 3: Effect of tool profile on the corrosion resistance of $\mathrm{Cu}-\mathrm{Al}$ joints.

\begin{tabular}{|c|c|c|c|c|c|c|}
\hline Tools & Conical & Triangle & Square & Pentagon & Hexagon & Base \\
\hline E pit & -528 & -576 & -565 & -551 & -534 & -642 \\
\hline
\end{tabular}

Table 1: Values of Pitting corrosion potential with different tool profiles.

This section showed that factors impacting the corrosion resistance could be divided into three categories, that is the alloy itself (such as alloy composition, mixed impurities, alloy structure, heat treatment, metal surface condition, stress and strain), the environment (such as corrosion medium, temperature, stress and equipment design) and the process and anti-corrosion measures.

\section{Methods Improving the Corrosion Resistance of $\mathrm{Cu}-\mathrm{Al}$ Joints}

After discussed the corrosion mechanism and the factors impacting the corrosion resistance of $\mathrm{Cu}-\mathrm{Al}$ joints, in this section, we discuss how to make a good use of these factors to protect $\mathrm{Cu}-\mathrm{Al}$ joints from corrosion. As abovementioned, the formation of corrosion attack was mainly resulted from heterogeneous chemical composition and microstructure of $\mathrm{Cu}-\mathrm{Al}$ joints, resulting in electrochemical corrosion. Hence methods decreasing heterogeneity could enhance corrosion resistance, such as the addition of the third element or compound, heat treatment, mechanical processing and weld tools design. For instance, Rao et al. successfully enhanced the corrosion resistance of $\mathrm{Cu}-\mathrm{Al}$ joints by using friction stir processing, which could carry out heat treatment and change grain size. Their study aimed at a kind of condition, where friction stir welding was not suitable such as thick plate welding and inaccessible locations. In such cases, it may be available for friction stir processing the fusion welds by using portable equipment. Besides it could enhance the fatigue property and refine the microstructure of $\mathrm{Cu}-\mathrm{Al}$ joints [14]. Wang et al. successfully decreased the corrosion cracks of aluminum joints by using laser shock penning (LSP). LSP changed the residual stress, refined the microstructure and enhanced the toughness and tensile properties, which in turn decrease the susceptibility of $\mathrm{Cu}-\mathrm{Al}$ joints to stress corrosion cracks [13].

\section{Conclusion}

In this review, we summarized the main recent research on the corrosion resistance of $\mathrm{Cu}-\mathrm{Al}$ joints, which included these aspects as followed: Researchers studied the corrosion behavior of $\mathrm{Cu}-\mathrm{Al}$ joints through simulating a variety of practical corrosion environments, and then observed the evolution of the structural morphology and tested the performance changes. The relationship between the evolution of the structural morphology in the $\mathrm{Cu}-\mathrm{Al}$ joint, the corrosion environment and corrosion mechanism was established. Factors impacting corrosion were explored. However, in these experiments, corrosion process was accelerated in the laboratory, which is not in agreement with the complex practical corrosion situation. In addition, most of research aimed at understanding the corrosion performance of $\mathrm{Cu}-\mathrm{Al}$ joints welded by using friction stir welding, ignoring other welding methods especially the brazing and laser welding, which have been used widely in $\mathrm{Cu}-\mathrm{Al}$ joining. In order to obtain a good welded joint, all kind of actual corrosion parameters should be collected as much as possible to establish a $\mathrm{Cu}-\mathrm{Al}$ corrosion database, and software simulation based on the actual corrosion parameters should be carried out for the purpose of saving materials and time.

\section{Funding Statement}

This work was founded by the International Cooperation Program of China (Grant numbers: 2015DFA50470) and the State Key Laboratory of Advanced Brazing Metals and Technology.

\section{References}

1. Ji F, Xue SB, Lou JY, Lou YB, Wang SQ (2012) Microstructure and properties of $\mathrm{Cu} / \mathrm{Al}$ joints brazed with $\mathrm{Zn}-\mathrm{Al}$ filler metals. Journal Transactions of Nonferrous Metals Society of China 22: 281-287.

2. Feng $\mathrm{F}$, Songbai $X$, Wei $D(2012)$ Reliability studies of $\mathrm{Cu} / \mathrm{Al}$ joints brazed with Zn-Al-Ce filler metals, Journal Materials \& Design 42: 156-163.

3. Xia C, Li Y, Puchkov UA, Gerasimov SA, Wang J (2008) Microstructure and phase constitution near the interface of Cu/Al vacuum brazing using Al Si filler metal. Journal Vacuum 82: 799-804.

4. Wang XG, Li XG, Yan FJ, Wang CG (2016) Effect of heat treatment on the interfacial microstructure and properties of Cu-Al joints. Journal Welding in the World 61: 187-196.1.

5. Wang XG, Yan FJ, Li XG, Wang CG (2016) Induction diffusion brazing of copper to aluminium. Journal Science and Technology of Welding and Joining 22: $170-175$

6. Lee WB, Bang KS, Jung SB (2005) Effects of intermetallic compound on the electrical and mechanical properties of friction welded $\mathrm{Cu} / \mathrm{Al}$ bimetallic joints during annealing. Journal of Alloys and Compounds 390: 212-219.

7. Bisadi H, Tavakoli A, Sangsaraki MT, Sangsaraki KT (2013) The influences of rotational and welding speeds on microstructures and mechanical properties of friction stir welded Al5083 and commercially pure copper sheets lap joints. Journal Materials \& Design 43: 80-88.

8. Watanabe T, Yanagisawa A, Konuma S, Yoneda A, Ohashi O (2010) Ultrasonic welding of Al-Cu and Al-SUS304. Study of ultrasonic welding of dissimilar metals (1st Report). Journal Welding International 13: 875-886.

9. Ye Z, Yang H, Huang J, Yang J, Chen S (2017) A novel Zn-Al-Si corrosion resistant filler metal for Cu/Al brazing. Journal Materials Letters 206: 201-204.

10. Guérin M, Andrieu E, Odemer G, Alexis J, Blanc C (2014) Effect of varying conditions of exposure to an aggressive medium on the corrosion behavior of the $2050 \mathrm{Al}-\mathrm{Cu}$-Li alloy. Journal Corrosion Science 85: 455-470.

11. Rao CV, Reddy GM, Rao KS (2015) Microstructure and pitting corrosion resistance of AA2219 Al-Cu alloy friction stir welds - Effect of tool profile. Journal Defence Technology 11: 123-131.

12. Wang $\mathrm{XH}$, Wang JH, Fu CW (2014) Characterization of pitting corrosion of $7 A 60$ aluminum alloy by EN and EIS techniques. Journal Transactions of Nonferrous Metals Society of China 24: 3907-3916.

13. Wang JT, Zhang YK, Chen JF, Zhou JY, Ge MZ, et al. (2015) Effects of laser shock peening on stress corrosion behavior of 7075 aluminum alloy laser welded joints. Journal Materials Science and Engineering 647: 7-14.

14. Rao KP, Ram GDJ, Stucker E (2010) Effect of friction stir processing on 
corrosion resistance of aluminum-copper alloy gas tungsten arc welds. Journal Materials \& Design 31: 1576-1580.

15. Wang J, Wang J, Ming H, Zhang Z, Han EH (2017) Effect of Temperature on Corrosion Behavior of Alloy 690 in High Temperature Hydrogenated Water. Journal of Materials Science \& Technology.

16. Moghaddam MS, Parvizi R, Davoodi A, Sabzevar MH, Imani A (2014) Establishing a correlation between interfacial microstructures and corrosion initiation sites in $\mathrm{Al} / \mathrm{Cu}$ joints by SEM-EDS and AFM-SKPFM. Journal Corrosion Science 79: 148-158.

17. Lim ABY, Neo WJ, Yauw O, Chylak B, Gan CL, et al. (2016) Evaluation of the corrosion performance of $\mathrm{Cu}-\mathrm{Al}$ intermetallic compounds and the effect of $\mathrm{Pd}$ addition. Journal Microelectronics Reliability 56: 155-161.

18. Shi H, Han EH, Liu F, Wei T, Zhu Z et al. (2015) Study of corrosion inhibition of coupled $\mathrm{Al} 2 \mathrm{Cu}-\mathrm{Al}$ and $\mathrm{Al} 3 \mathrm{Fe}-\mathrm{Al}$ by cerium cinnamate using scanning vibrating electrode technique and scanning ion-selective electrode technique. Journal Corrosion Science 98: 150-162.

19. Logan HL (1952) Film-Rupture Mechanism of Stress Corrosion. Journal of Research of the National Bureau of Standards 48: 7 .
20. Edeleanu C, Forty AJ (1960) Some observations on the stress-corrosion cracking of $\alpha$-brass and similar alloys. Journal Philosophical Magazine 5: 10291040

21. Popov BN (2015) Stress Corrosion Cracking, pp: 365-450.

22. Wu Y, Subramanian KN, Barton SC, Lee A (2017) Electrochemical studies of $\mathrm{Pd}$-doped $\mathrm{Cu}$ and $\mathrm{Pd}$-doped $\mathrm{Cu}-\mathrm{Al}$ intermetallics for understanding corrosion behavior in wire-bonding packages. Journal Microelectronics Reliability 78: 355-361.

23. Osorio WR, Freire CM, Caram R, Garcia A (2012) The role of Cu-based intermetallics on the pitting corrosion behavior of $\mathrm{Sn}-\mathrm{Cu}, \mathrm{Ti}-\mathrm{Cu}$ and $\mathrm{Al}-\mathrm{Cu}$ alloys. Journal Electrochimica Acta 77: 189-197.

24. Rao CV, Reddy GM, Rao KS (2015) Influence of tool pin profile on microstructure and corrosion behaviour of AA2219 Al-Cu alloy friction stir weld nuggets. Journal Defence Technology 11: 197-208.

25. Warner JS, Gangloff RP (2012) Molybdate inhibition of corrosion fatigue crack propagation in precipitation hardened Al-Cu- Li. Journal Corrosion Science 62 $11-21$. 